\title{
CONCLUSION \\ The role of the Quebec English School Boards Association in the context of diversity and critical issues in education
}

\author{
David Birnbaum (Quebec English School Boards Association)
}

\section{INTRODUCTION}

The Quebec English School Boards Association (QESBA) has played a constructive role in the volatile public debate on the subject of educational challenges to diversity in the most recent decade. Its member school boards and schools have, for the most part, responded wisely, compassionately and positively to the challenges and opportunities of diversity in the classroom.

We will begin with a very quick overview of our school network and discuss our understanding of the current context. We will also quickly review some of QESBA's interventions on this subject, offer some examples of the general approach of our English schools, guess at some continuing challenges and finally, conclude with some observations.

\section{WHO ARE WE?}

The Quebec English School Boards Association (QESBA) represents nine member English school boards who serve some 110,000 students in 350 elementary, high schools and adult centres across the province of Quebec. The 350 English public schools of Quebec represent a profile of diversity. There are one-room school houses on Entry Island in the Magdalen Islands (nearly 1,400 $\mathrm{km}$ from Montreal) and in Vaudreuil-Soulanges, which is only 30 minutes from Montreal. On the other hand, large high schools of over 1,000 students can be found in urban areas, as well as in smaller towns of the Eastern Townships and the South Shore of Montreal.

\section{THE CURRENT CONTEXT}

A defining characteristic of our school network is its recognition and advancement of cultural, racial and religious diversity. The English public schools in Montreal have a long tradition of welcoming students of diverse backgrounds. The notion of bringing together a wide variety of languages, races, religions and cultures has been central to English schooling for many years.

Of course, prior to the adoption of the Charter of the French Language in 1977, a disproportionately large percentage of new immigrants to Quebec were registered in English schools. Before then, there was a period when almost all non-Catholics, whether they were new students, immigrants or Canadian, were 
discouraged from entering the French speaking school system and were directed to the English system. However, this is no longer the case. It has been ten years since Quebec school boards were re-organized along linguistic rather than confessional lines. Nowadays, access to English schools is essentially limited to those children whose parents studied in the English language in Canada. Consequently, most children do not qualify for this clause and the diversity of the English school population has been less pronounced in the ensuing years. Nevertheless, our schools, particularly in metropolitan Montreal, continue to welcome eligible students with roots in many different cultural communities.

As mentioned, Quebec's English schools, particularly in the greater Montreal area, have had the luxury of building upon a few generations of multicultural/multiracial diversity in the classroom. It has undoubtedly taken some time - and the challenge is still present; the face of school and board administration is starting to reflect this diversity. We are not newcomers to this reality. To some extent, we have to acknowledge that we were bystanders, and on occasion, bemused and somewhat discouraged as politics and posturing, largely, led us to some unusual and unfocused public hysterics over kirpans and kipas in Quebec. In my view, the real explosion started when one political leader saw opportunity in distorting diversity and, basically, cheerleading for insecurity, then, the other leaders - with major media in tow-set off for the races to frame the debate themselves.

Thus, begot the Bouchard-Taylor Commission $^{29}$ on reasonable accommodation, and a public blood-letting of dubious value, many would say. The process was somewhat messy but QESBA would say that the final report deposited by the two brilliant and thoughtful Chairs was ultimately important and useful.

The public hearings of the Commission were not, to put it mildly, your typical sessions of varied discourse; many, in fact, some interventions bordered on racist polemics from angry and disenfranchised individuals. Free speech has its limits; and those limits got somewhat stretched on more than one occasion. Notwithstanding, Quebec society survived after showing the collective courage to address some very fundamental questions. We are probably better for it. Even if the current context bypassed educators and institutions, we are now facing the current realities. Very few newcomers to Quebec have access to English schools ever since the adoption of the French Language Charter in 1977. In our English schools, the underlying preoccupation over the security of the French language

\footnotetext{
${ }^{29}$ The Bouchard-Taylor Commission was established in 2007 to provide recommendations to the government in response to the reasonable accommodation debates in Quebec. q.v. http://www.accommodements.qc.ca/indexen.html
} 
and common culture in Quebec is not a challenge. Furthermore, the rapid deconfessionalization, not to mention the de-Catholization of our school system, is also much less present as an issue in our English schools. While it didn't get as much ink as kipas and kirpans, the fading place of the Catholic Church in Quebec, against the counterpoint of some prominent and diverse religious practices from across the globe, has caused much ambivalence and concern in French Quebec. This dynamic is not of much significance in our English school community. Certainly, there are issues when questions of religious leave arise for teachers, or at those times when Christmas and Hallowe'en come around each year...and our students must wrestle with the same issues of prejudice, bullying and stereotyping as their French school colleagues. But, it is really important to remember that this whole subject is generally easier for us: there is not a collective linguistic and cultural insecurity at play, nor is the disappearance of a Catholic orientation a major factor for our English school network. It probably allows our school system to deal more directly with diversity. However, we have our own set of particularities to bring to the discussion on diversity and reasonable accommodation.

\section{WHY DO THESE DISTINCTIONS MATTER?}

In reference to the reasonable accommodation, QESBA made three interventions to the Bouchard-Taylor Commission that might help illustrate this distinctiveness.

First, it was essential to specify that we must prepare our students, whatever their backgrounds, for the realities of a predominantly French Quebec. There is a strong consensus in our English school communities about this most essential of tasks. As we grapple with our own challenges of retaining and strengthening our English speaking communities across Quebec, our English schools must and do play a very positive role in promoting the integration of their students into a predominantly French Quebec society.

Second, QESBA offered the Bouchard-Taylor Commission its views on the new Ethics and Religious Culture (ERC) program. Here again, there is perhaps a greater receptivity to new programs in our schools than in the French sector. We noted that the new program is a constructive final step in laicization of the public school system. The reformed school program prescribes a wellconsidered and reflective look at modern Quebec, one that is respectful of its common values and history. In addition, we pointed to the preamble to the program as something of a roadmap for all of us when it comes to addressing diversity in education. I think it's worth quoting here: 
Like many democratic societies, Québec is characterized by growing pluralism. Evident in the diversity of values and beliefs held by individuals and groups, this diversity contributes to shaping Québec culture. An important factor of enrichment, diversity can also be a source of tension. Living together in today's society requires that we collectively learn to build on this diversity. It is therefore important to develop an awareness of this diversity and to reflect upon and take actions that foster community life. The Ethics and Religious Culture program endeavours to contribute to this learning. (p. 295). ${ }^{30}$

Third, QESBA offered the Bouchard-Taylor Commission its views on the heated issue of gender equality, and perceptions surrounding it. It is important that it be mentioned here because gender equality seems to have become a lightning rod for tensions between "us" and "them" which is a sad but usually inaccurate division between old-stock and new Quebecers.

QESBA has no doubt that the protection of workers against discrimination based on gender can and must be fully assured under existing laws. Nevertheless, we cannot agree with those who have suggested that Quebec's Charter of Human Rights be changed in order to prohibit all public sector employees, including teachers, from wearing any clearly identifiable religious symbols while on the job. The suggestion, in response to women choosing to wear the hijab, came from the Conseil de la statut de la femme (Council of the Status of Women). To suggest that such symbols automatically indicate the subjugation of women is incorrect at best and pejorative at worst. Second, it invites the retrograde impression that there is only one way to be a Quebecer. That, thankfully, runs contrary to the pedagogical vision of the Ethics and Religious Culture Program that was implemented in September 2010, and we believe, contrary to the generous instincts of most Quebecers. If anything, Quebec's public and para-public institutions have a greater role to play in better demonstrating that they are inclusive in who they hire and how they serve the public. When it comes to education, surely we want our teachers to look just like the diversity of modern Quebec from which our children come.

\section{THE GENERAL APPROACH OF OUR ENGLISH SCHOOLS}

In the area of diversity and reasonable accommodation, a few examples can reflect the general approach of the English school system. The English Montreal

\footnotetext{
${ }^{30}$ For access to the Ethics and Religious Culture section of Quebec Elementary Education Program see: https://www7.mels.gouv.qc.ca/DC/ECR/pdf/ecr_elementary.pdf
} 
School Board (EMSB), where more than 50 ethno-cultural groups are represented, is the most diverse of Quebec's nine school boards. The proactive tone of its policy on multicultural/multiracial education is fairly emblematic of the English-sector approach: The following are among the general principals in the policy: "The EMSB is committed to the development of policies that foster acceptance and understanding of all students and encourage an appreciation of human diversity. And, "The EMSB recognizes that ethnic and cultural diversity are positive features of Quebec and Canadian societies." The policy is put into practice with measures to promote the retention of languages and cultures of origin, in-service training for school personnel and volunteers on cultural diversity and its impact on education, and active equitable recruitment practices.

To that effect, our Central Québec School Board, which serves a much more homogeneous population, refrains from any organized Hallowe'en activities or birthday card exchanges in schools where a number of families present are Jehovah's Witnesses. Lester B. Pearson School Board permits the wearing of the hijab, and in many high schools a prayer room has been set aside for Muslim students. The Board also commits itself to providing resources for extracurricular activities that promote intercultural awareness. At some adult and vocational centres within the Sir Wilfrid Laurier School Board, intercultural lunches are occasionally sponsored. This is a significant gesture for these students, given that they might not have benefitted from earlier school experiences of this nature within our system. Across our English boards, accommodation for religious observance by all categories of staff has generally been possible, with no undue conflict or inconvenience. The general policy is that two or three days are provided for religious leave, by local arrangement.

\section{SOME CONTINUING CHALLENGES}

There are, of course, several issues that continue to challenge us. Demands on teachers and school administrators never end, and the training, support and compensation they receive are admittedly, not always sufficient.

Managing today's classroom, with students at various levels of experience and potential continues to pose problems.

Acknowledging and embracing diversity which is central to giving every student an equal chance at learning and self-worth cannot always be priority number one. And since we accept student teachers from the English school system for their practicum, we are aware that education faculties are charged with preparing tomorrow's teachers for a classroom in constant flux. Again, the issues we are discussing today do not necessarily get the time they require. 
The question arises whether the Ministry of Education is doing enough to fund and facilitate a public school system that values diversity, and is positioning it as a complement rather than a threat to Quebec's traditional orientations and background.

On the other hand, are Quebec's ethno-cultural communities themselves and the families that comprise them each doing enough to embrace and understand Quebec's particularities, its history and accomplishments?

Have the media, in the mainstream and in cyber-space, been positive and responsible partners in the public debate on diversity in education and in the wider Quebec society? At times they have been sensationalist.

The story of Herouxville ${ }^{31}$ is one of the more infamous stops on Quebec's bumpy journey towards reasonable accommodation. Herouxville housed one short-time resident of Haitian origin, apparently. Nevertheless, its Town Council saw the sky falling because newcomers were taking over. A small municipality in Quebec, Herouxville "received international attention in January 2007 when its town council passed controversial measures concerning practices which the residents deemed unsuitable for life in Herouxville for potential new immigrants, despite the fact that the town has no immigrant population. Herouxville has a small population of 1,338 residents who are entirely White, francophone, and nominally Catholic" (Wikipedia).

Well, Herouxville is part of Quebec, small and big towns like it are part of who we are collectively. It's a difficult prescription, but whatever we must do to celebrate our differences where they occur, we must also apply to the many Quebec places where they don't.

\section{SOME OBSERVATIONS}

To conclude, some observations need to be addressed. First, Quebec and all Quebecers must look at diversity in education as everybody's business. Too often, these matters continue to play out on the margins. Most of us are not deeply devout practitioners of our religious beliefs. And, surely, most of us don't view such practices as a threat to Quebec's majority language and culture. However, the discussion of reasonable accommodation too often gets stuck between those two positions, rather than at the gravitational centre of our society. That is a disservice to everyone. Even some of our vocabulary reflects a bad dichotomy, in my view, of winners and losers. Such words as tolerance or accommodation do not translate to us that diversity is a benefit. It seems to me that the key words to adapt our schools to diversity must be: empathy,

\footnotetext{
${ }^{31}$ For more information on the story of Herouxville see: http://en.wikipedia.org/wiki/H\%C3\%A9rouxville,_Quebec
} 
compassion, self-confidence, knowledge and celebration of variance. These words make for a more cohesive society and a stronger sense of mutual understanding. Second, and here, education can perhaps provide leadership: we need to find models to deliver and practice the celebration of diversity in those areas of the province where very little diversity actually exists. It is not an easy challenge. But as usual, if our schools don't play a leadership role, will anyone else do the serious learning necessary for us to move forward? History would tell us, no.

David Birnbaum is the Executive Director of the Quebec English School Boards Association. These are his own reflections, and not necessarily those of the Association. He can be contacted at davidbir@sympatico.ca.

\section{FINAL COMMENTS BY DENISE LUSSIER AND RATNA GHOSH:}

A greater understanding of the relationship of religion and education is essential in order to generate a common conceptual framework for understanding issues of conflicts beyond the politics of difference. One way to do this would be to undertake a collaborative international research project to be carried out with schools of several pluralist democratic societies in North America and Europe. With a large-scale research project, the attempt would be to document best practices which will prompt discussion of various possibilities and policies to foster peace in the world through education. Research and scholarship on issues of social integration tend to overlook the participation of youth. The development of a two-stage collaborative project proposal could first focus on each country having empirical research on questions which seek the various points of view of youth. For example: How do youth of religious and racial minorities think of difference with respect to their identity formation and integration in pluralist democratic societies? How do students react to the strategies that schools employ to create and sustain socially just and inclusive environments in evolving multicultural, multiracial and multi-faith societies? In a second stage, and taking into account the data from the first phase, research should aim for the development of a systematic approach applicable to the design of new curricula, the integration of new pedagogical approaches, and the creation of new types of textbooks in order to foster social cohesiveness. 